\title{
PENGARUH PENERAPAN MODEL PEMBELAJARAN \\ KOOPERATIF TIPE STAD BERBANTUAN MEDIA KARTU \\ DOMINO TERHADAP PRESTASI BELAJAR MATEMATIKA \\ SISWA SMA
}

\author{
I Putu Ade Andre Payadnya \\ Universitas Mahasaraswati Denpasar \\ adeandre@unmas.ac.id \\ Putu Suarniti Noviantari \\ Universitas Mahasaraswati Denpasar \\ pts.noviantari@yahoo.com \\ I Gusti Agung Ngurah Trisna Jayantika \\ Universitas Mahasaraswati Denpasar \\ trisnajayantika17@gmail.com \\ I Gusti Ayu Virly Permatasari \\ Universitas Mahasaraswati Denpasar \\ virlyp29@gmail.com
}

\begin{abstract}
This study aimed to determine whether the mathematical learning achievement of students who learned using cooperative learning mode of STAD assisted by domino card is better than the students who learned using conventional learning model. The type of this research was quasi-experimental research in which the post-test only controlled group design. The population of this research was students of $11^{\text {th }}$ grade of SMA Negeri 6 Denpasar in academic year 2018/2019 totaling 321 students who were distrbuted into 9 classes. The sample was taken using Cluster Random Sampling technique where two classes were chosen as experimental class and control class. Data of students' mathematical learning achievement were collected by test method. Data were analyzed using one-tail t-test with a significance level of 5\%. The results of data analysis showed that the mathematics learning achievement of students who learned using cooperative learning model of STAD assisted by domino card was better than the mathematics learning achievement of students who learned using the conventional learning model in $11^{\text {th }}$ grade of SMA Negeri 6 Denpasar in academic year 2018/2019.
\end{abstract}

Keywords: Mathematical Learning Achievement, Cooperative Learning Model of STAD, Domino Card Media.

\section{PENDAHULUAN}

Pendidikan merupakan hal yang sangat penting bagi manusia sebagai wahana untuk pembangunan sumber daya manusia yang berkualitas. Kualitas pendidikan sangat dipengaruhi oleh kualitas dari tenaga pendidiknya. Tenaga pendidik yang dimaksud adalah guru. Guru harus dapat membimbing siswa sedemikian rupa sehingga mereka dapat mengembangkan pengetahuannya sesuai dengan struktur pengetahuan bidang studi yang dipelajari dalam hal ini pelajaran matematika. 
Pelajaran matematika adalah salah satu bidang ilmu yang memegang peranan sangat penting dalam kehidupan sehari-hari. Banyak bidang ilmu yang sangat memerlukan matematika untuk perkembangannya. Oleh karena itu, pemahaman terhadap matematika mutlak diperlukan dan konsep-konsep matematika harus dipahami dengan betul dan benar sejak dini (Payadnya dkk, 2014). Pada proses pembelajaran matematika diperlukan kemampuan dan pemahaman materi yang baik oleh siswa sehingga, prestasi belajar matematika pun akan baik juga.

Prestasi belajar matematika memiliki peranan penting dalam pembelajaran yang dapat menunjukkan tingkat kemampuan dan pemahaman siswa dalam belajar matematika. Namun, pelajaran matematika masih sering diasumsikan sebagai pembelajaran yang sulit (Payadnya dkk, 2016). Keberadaan asumsi tersebut membentuk pola pemahaman pada setiap siswa bahwa pelajaran matematika adalah pelajaran yang menakutkan yang berakibat pada prestasi belajar siswa yang kurang memuaskan. Hal tersebut terbukti dari laporan survei Programme for International Student Assesment (PISA) pada tahun 2012 dimana Indonesia berada di peringkat 38 dari 40 negara, dengan skor rerata 360 dan rerata skor internasional adalah 500. Sedangkan pada tahun 2015, prestasi belajar matematika siswa-siswi Indonesia masih tergolong rendah dimana Indonesia berada di peringkat 62 dari 72 negara yang yang dievaluasi dengan rerata skor 386 (Kemdikbud, 2016).

Banyak faktor yang menyebabkan prestasi belajar matematika rendah. Menurut Syah (2008), menjelaskan bahwa prestasi belajar dipengaruhi oleh 3 faktor antara lain, faktor dalam (internal), faktor luar (eksternal) dan faktor pendekatan belajar. Model pembelajaran merupakan salah satu faktor eksternal yang mempengaruhi pembelajaran matematika dalam kelas. Model pembelajaran yang marak digunakan dalam pendidikan selama ini adalah pembelajaran kontekstual yang merujuk pada model pembelajaran konvensional.

Perlu adanya kreativitas guru dalam menggunakan model pembelajaran yang kreatif dan juga efektif (Payadnya, 2018). Terdapat banyak jenis model pembelajaran yang kreatif dalam dunia pendidikan yang kita kenal dengan sebutan pembelajaran kooperatif. Model pembelajaran kooperatif yang lebih menekankan pada interaksi antar siswa adalah model pembelajaran kooperatif tipe STAD (Cahyanto, 2013; Tipa dkk, 2016). Model pembelajaran kooperatif tipe STAD merupakan salah satu pendekatan dalam pembelajaran kooperatif yang paling sederhana, yang dikembangkan oleh Robert Slavin di Universitas John Hopkin, dan merupakan sebuah pendekatan yang baik untuk guru yang baru menerapkan model pembelajaran kooperatif di kelas. Pembelajaran kooperatif tipe STAD dibagi menjadi lima komponen utama yaitu: presentasi kelas (class presentations), belajar kelompok (teams), kuis (quizzes), peningkatan skor individu (individual improvement scores), dan penghargaan kelompok (team recognition) (Slavin, 2010:143).

Selain dengan model pembelajaran kooperatif tipe STAD bantuan dengan menggunakan media kartu domino mengakibatkan proses pembelajaran akan semakin baik. Arsyad (2009) menyatakan bahwa dalam suatu proses belajar mengajar dua unsur yang amat penting adalah metode mengajar dan media pembelajaran. Kedua aspek ini saling berkaitan, pemilihan salah satu metode mengajar tertentu akan mempengaruhi jenis media pembelajaran yang sesuai. 
Berdasarkan latar belakang yang diuraikan, tujuan yang ingin dicapai dari penelitian ini adalah untuk mengetahui pengaruh model pembelajaran kooperatif tipe STAD berbantuan media kartu domino terhadap prestasi belajar matematika siswa di kelas XI SMA Negeri 6 Denpasar Tahun Pelajaran 2018/2019.

\section{METODE PENELITIAN}

Jenis penelitian yang dilakukan adalah penelitian eksperimen. Jenis penelitian ini adalah penelitian eksperimen semu (quasi experimen). Penelitian ini menggunakan desain penelitian Quasi Experimental. Desain penelitian yang digunakan adalah Post Test Only Control Group Design, dalam desain ini terdapat dua kelompok yang dipilih secara random. Kelompok pertama diberi perlakuan dan kelompok lain tidak. Kelompok yang diberi perlakuan disebut kelompok eksperimendan kelompok yang tidak diberi perlakuan disebut kelompok kontrol. Setelah perlakuan, diberikan post-test pada kedua kelompok. Berikut adalah desain penelitiannya.

Tabel 01. Skema Posttest Only Control Group Design

Keterangan :

\begin{tabular}{|c|c|c|c|}
\hline & Kelas & Treatment & Posttest \\
\hline $\mathrm{R}$ & Eksperimen & $\mathrm{X}$ & $\mathrm{T}_{2}$ \\
\hline $\mathrm{R}$ & Kontrol & - & $\mathrm{T}_{2}$ \\
\hline \multicolumn{3}{|c}{ (Payadnya \& Jayantika, 2018:10) }
\end{tabular}

$\mathrm{R}=$ kelompok yang dipilih secara

Random

$\mathrm{X}=$ perlakuan

$\mathrm{T}_{2}=$ prestasi belajar pada siswa setelah mendapat perlakuan (post-test) pada kelompok eksperimen/kontrol

Populasi pada penelitian ini adalah siswa kelas XI SMA Negeri 6 Denpasar Tahun Pelajaran 2018/2019 yang berjumlah sebanyak 321 siswa yang tersebar pada 9 kelas. Sampel pada penelitian ini dipilih dengan teknik Cluster Random Sampling. Dua kelas yang terpilih sebagai sampel adalah kelas XI IPS 2 sebagai kelas eksperimen dan kelas XI IPS 1 sebagai kelas kontrol.

Instrumen yang digunakan pada penelitian ini adalah tes objektif berupa soal pilihan ganda untuk mengetahui prestasi belajar pada kelompok eksperimen dan kelompok kontrol yang akan dibandingkan. Sebelum digunakan untuk evaluasi, pada soal tes dilakukan uji validitas isi (uji pakar) oleh dua orang validator. Setelah itu soal tes diuji cobakan di kelas uji coba yaitu kelas XII MIPA 1 dengan tujuan agar soal tes memenuhi persyaratan validitas, reliabilitas, indeks kesukaran dan daya beda yang baik.

Data dikumpulkan dengan teknik dokumentasi, untuk memperoleh kemampuan awal siswa, teknik tes (post-test) untuk memperoleh prestasi belajar siswa, teknik observasi untuk mengamati evektifitas dari penerapan model pembelajaran dan teknik wawancara untuk menegetahui keberhasilan model pembelajaran. Pengujian hipotesis menggunakan uji $\mathrm{t}$ satu pihak dengan uji prasyarat yaitu uji normalitas dan uji homogenitas. Uji

normalitas menggunakan uji chi-kuadrat dan untuk menguji homogenitas varians digunakan uji F. Kriteria pengujian varians yaitu varians dikatakan homogen apabila $F_{\text {hit }}$ $<\mathrm{F}_{\text {tabel }}$ dengan taraf signifikasi 5\%.

Adapun hipotesis penelitian ini adalah sebagai berikut. 
$\mathrm{H}_{\mathrm{a}}$ : Prestasi belajar matematika siswa yang menggunakan model pembelajaran kooperatif tipe STAD berbantuan media kartu domino lebih baik dari prestasi belajar matematika siswa yang menggunakan pembelajaran konvensional di kelas XI SMA Negeri 6 Denpasar Tahun Pelajaran 2018/2019.

$\mathrm{H}_{0}$ : Prestasi belajar matematika siswa yang diajar dengan model pembelajaran kooperatif tipe STAD berbantuan media kartu domino tidak lebih baik dari prestasi belajar matematika siswa yang menggunakan model pembelajaran konvensional di kelas XI SMA Negeri 6 Denpasar Tahun Pelajaran 2018/2019

Secara statistik, hipotesis tersebut dapat dirumuskan sebagai berikut:

$H_{a}: \bar{X}_{1}>\bar{X}_{2}$ melawan $H_{0}: \bar{X}_{1} \leq \bar{X}_{2}$

Kriteria pengujian adalah tolak $H o$ jika $t_{\text {hit }} \geq t_{(1-\alpha)}$ dimana $t_{(1-\alpha)}$ didapat dari tabel distribusi $t$ pada taraf signifikasi $\alpha=5 \%$ dengan derajat kebebasan $\mathrm{dk}=\left(n_{1}+n_{2}-2\right)$.

\section{HASIL PENELITIAN DAN PEMBAHASAN \\ Hasil Penelitian}

Secara deskriptif, data prestasi belajar matematika siswa kelas eksperimen dan kelas kontrol dapat digambarkan dalam bentuk histogram seperti pada Gambar 01 dan Gambar 02.

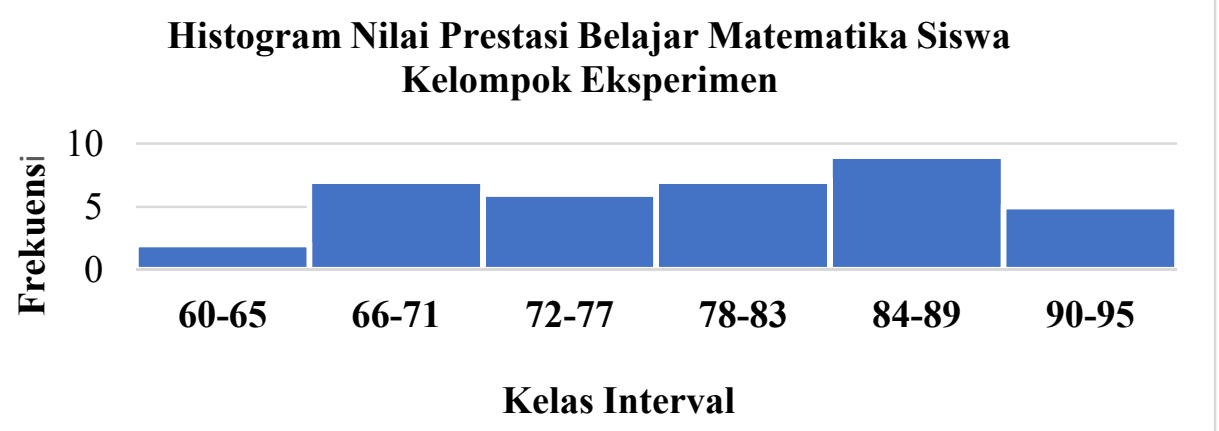

Gambar 01. Histogram Nilai Prestasi Belajar Matematika Siswa Kelompok Eksperimen

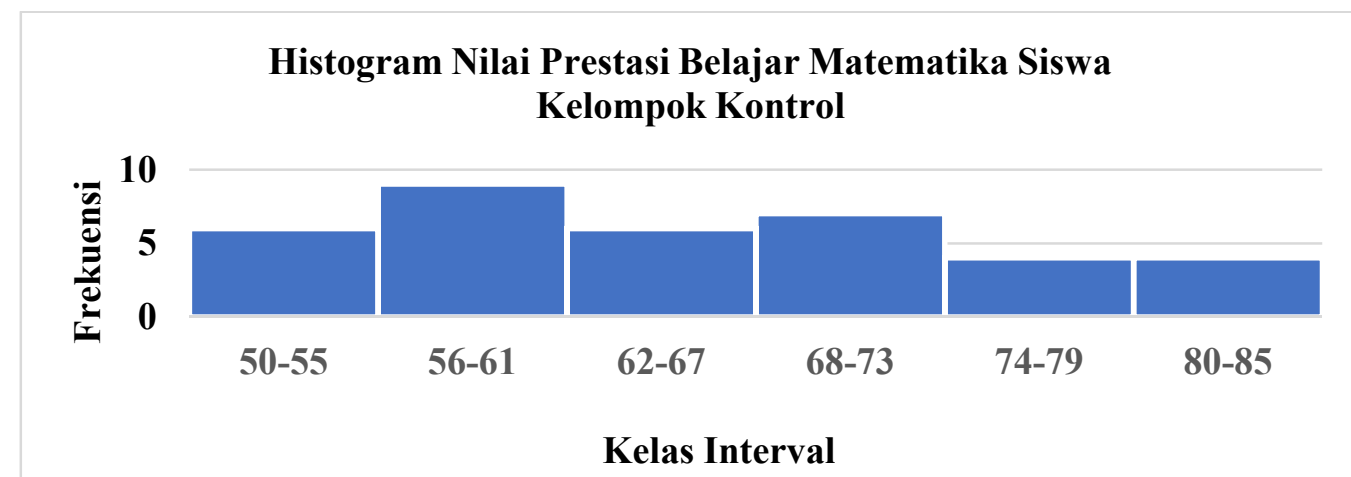

Gambar 02. Histogram Nilai Prestasi Belajar Matematika Siswa Kelompok Kontrol

Rata-rata nilai prestasi belajar matematika siswa pada kelompok eksperimen adalah $\bar{X}=79,58$ dengan standar devisiasi yaitu $\mathrm{SD}=8,97$ dan rata-rata nilai prestasi belajar matematika siswa pada kelompok kontrol adalah $\bar{X}=65,56$ dengan standar devisiasi yaitu $\mathrm{SD}=9,01$.

Selanjutnya hasil analisis data prestasi belajar matematika kedua kelompok dilakuakan uji prasyarat diperoleh: 1) Dengan uji normalitas menggunakan uji chikuadrat kelompok eksperimen berdistribusi normal $\left(\chi_{\text {hit }}^{2}=9,29 \leq \chi_{t}^{2}=11,07\right)$ 
dan kelompok kontrol berdistribusi normal $\left.\left(\chi_{\text {hit }}^{2}=8,96 \leq \chi_{t}^{2}=11,07\right) 2\right)$ Dengan uji F, kedua kelompok adalah homogen $\left(F_{\text {hit }} \quad=1,01<F_{t} \quad=1,76\right)$

Hasil uji analisi t dengan taraf signifikasi 5\% diperoleh $t_{\text {hitung }}>t_{\text {tabel }}$ yaitu 6,61 $>$ 1,667 untuk $d k=70$. Maka $H_{0}$ ditolak dan $H_{a}$ diterima. Dengan kata lain prestasi belajar matematika siswa yang menggunakan model pembelajaran kooperatif tipe STAD berbantuan media kartu domino lebih baik dari prestasi belajar matematika siswa yang menggunakan pembelajaran konvensional di kelas XI SMA Negeri 6 Denpasar Tahun Pelajaran 2018/2019.

\section{Pembahasan}

Prestasi belajar matematika siswa kelompok eksperimen lebih memuaskan apabila dibandingkan dengan prestasi belajar matematika siswa kelompok kontrol yang ditunjukkan oleh nilai rata-rata kelompok eksperimen lebih baik daripada nilai rata-rata kelompok kontrol. Hal ini terjadi karena model pembelajaran kooperatif tipe STAD dapat membuat siswa menjadi lebih aktif dalam mengkonstruksi pengetahuannya sendiri (Cahyanto, 2013). Selain itu, bantuan media pembelajaran yang dalam hal ini berupa kartu domino dapat membuat pembelajaran menjadi semakin menarik sehingga meningkatkan minat dan motivasi siswa (Arsyad, 2009). Dalam pembelajaran, siswa diarahkan untuk mengerjakan LKS yang sudah disiapkan sebelumnya. Apabila siswa mengalami kesulitan dalam mengerjakan LKS tersebut, maka guru membimbing siswa dalam memecahkan persoalan yang tidak dimengerti oleh siswa. Pada konteks ini siswa merasa lebih terbimbing dan lebih mudah dalam memahami persoalan yang dihadapi (Payadnya dkk, 2014). Setelah mengerjakan LKS, guru meminta masing-masing perwakilan kelompok untuk mempresentasikan hasil diskusinya di depan kelas dan siswa yang lainnya menanggapi. Guru memberikan kesempatan kepada siswa untuk menanggapi hasil yang dikerjakan oleh perwakilan kelompok diskusi siswa yang berada di depan. Hasil diskusi semua kelompok sangat memuaskan dan setiap perwakilan kelompok dapat menyampaikan materi dengan baik.

Keterlibatan siswa dalam proses pembelajaran membuat siswa menjadi semakin aktif, dengan demikian siswa menjadi kuat ingatannya akan pelajaran dan prestasi belajar dapat ditingkatkan (Payadnya \& Jayantika, 2018). Kemudian dilanjutkan dengan pemberian soal kuis untuk mengukur tingkat pemahaman siswa terhadap materi pelajaran yang sedang dibahas. Dalam mengerjakan soal kuis ini, siswa diwajibkan untuk mengerjakannya secara mandiri dan tidak mencontek pekerjaan temannya. Keunggulan dari pengerjaan secara individu ini akan membuat siswa belajar menyelesaikan permasalahannya sendiri dengan usaha mereka sendiri. Sebelumnya, pada model pembelajaran kooperatif tipe STAD berbantuan media kartu domino ini siswa diminta untuk lebih teliti, kreatif dan aktif dalam menjawab soal dengan berbantuan media kartu domino dan menanggapi materi pelajaran yang sedang dibahas. Hal ini yang menyebabkan nilai prestasi belajar siswa dalam pelajaran matematika meningkat karena siswa akan lebih aktif dalam hal bertanya sesuatu yang tidak dipahaminya, baik kepada teman sejawatnya maupun kepada guru. Hal tersebut membuat siswa menjadi lebih dihargai dan lebih percaya diri dalam mengikuti proses pembelajaran di dalam kelas.

Berbeda halnya dengan model pembelajaran konvensional. Bentuk dari pendekatan pembelajaran ini berorientasi kepada guru yang berperan sebagai pusat 
informasi (teacher centered). Materi yang disampaikan oleh guru sangat monoton sehingga konsep-konsep tersebut harus selalu dihapalkan sehingga membuat siswa tidak berpikir kreatif. Hal ini terlihat pada saat mengerjakan soal kuis sebagian siswa tidak dapat menjawab semua soal. Untuk siswa yang pandai dapat dengan mudah mengerjakan soal, namun siswa yang kurang pandai mengalami kesulitan. Sementara itu siswa seringkali enggan atau malu bertanya kepada gurunya apabila ada materi pelajaran yang kurang dipahami. Sehingga guru mengalami kesulitan untuk menyimpulkan bahwa siswa mengerti atau tidak pada apa yang dijelaskan oleh guru.

Berdasarkan uraian di atas, prestasi belajar matematika siswa yang menggunakan model pembelajaran kooperatif tipe STAD berbantuan media kartu domino lebih baik dari prestasi belajar matematika siswa yang menggunakan model pembelajaran konvensional di kelas XI SMA Negeri 6 Denpasar Tahun Pelajaran 2018/2019.

\section{SIMPULAN}

Berdasarkan hasil penelitian dan pembahasan yang telah diuraikan di depan, maka dapat disimpulkan bahwa prestasi belajar matematika siswa yang menggunakan model pembelajaran kooperatif tipe STAD berbantuan media kartu domino lebih baik dari siswa yang mnggunakan model konvensional di kelas XI SMA Negeri 6 Denpasar tahun pelajaran 2018/2019.

Adapun beberapa saran yang dapat disampaikan: 1) Kepada para pengajar bidang studi matematika disarankan agar dapat menerapkan model pembelajaran kooperatif tipe STAD berbantuan media kartu domino dalam pelaksanaan proses pembelajaran, khususnya pada kelas XI SMA. 2) Kepada para pengajar bidang studi lain juga dapat menerapkan model pembelajaran kooperatif tipe STAD berbantuan media kartu domino agar proses pembelajaran lebih aktif. 3) Kepada peneliti lain yang berminat dapat melakukan penelitian mengenai model pembelajaran kooperatif tipe STAD berbantuan media kartu domino pada bidang dan jenjang yag berbeda.

\section{DAFTAR PUSTAKA}

Arsyad, A. (2009). Media Pembelajaran. Jakarta: Rajawali Pers

Cahyanto, P. (2013). Upaya Peningkatan Pembelajaran Matematika dalam Menentukan Volume Tabung melalui Pembelajaran Kooperatif Tipe STAD pada Siswa Sekolah Dasar. Jurnal Penelitian Pendidikan Guru Sekolah Dasar, 1(2), 111-114

Kemdikbud. (2016). Peringkat dan Capaian PISA Indonesia Mengalami Peningkatan,(Online), (http://kemdikbud.go.id/main/blog/2016/12/peringkat-dancapaian-pisa-indonesia-mengalami-peningkatan diakses 30/02/2019

Payadnya, I. P. A. A, Suparta, I. N, \& Mertasari, N. M. S. (2014). Pengaruh Penerapan Model Pembelajaran Kooperatif Dengan Metode Team Quiz Terhadap Pemahaman Konsep Matematika Siswa Kelas VIII SMP Negeri 2 Singaraja. Jurnal Pendidikan Matematika Undiksha, 2(1). doi: http://dx.doi.org/10.23887/jjpm.v2i1.4001 
Payadnya, I. P. A. A, Suparta, I. N \& Suweken, I. G. (2016). Pengembangan Desain Pembelajaran Berbantuan Pertanyaan What-If Dalam Upaya Meningkatkan Kemampuan Siswa Menangani Permasalahan Matematika Terbuka. Jurnal Pendidikan dan Pembelajaran Matematika Indonesia, 5(1), 18-28. doi: https://doi.org/10.23887/jppm.v5i1.2131

Payadnya, I. P. A. A. (2018). Investigation of students' mathematical reasoning ability in solving open-ended problems. Journal of Physics: Conference Series, 1200(1), 19. doi:10.1088/1742-6596/1200/1/012016

Payadnya, I. P. A. A \& Jayantika, I. G. A. N. T. (2018). Analisis Kesulitan Siswa Dalam Menangani Permasalahan Matematika Terbuka (Mathematic Open-Ended Problems). Jurnal Santiaji Pendidikan, 8(2), 90-99. Diakses dari http://ejournal.unmas.ac.id/index.php/jsp/article/view/167/159

Payadnya, I. P. A. A \& Jayantika, I. G. A. N. T. (2018). Panduan Penelitian Eksperimen Beserta Analisis Statistik dengan SPSS. Yogyakarta: Deepublish.

Slavin, R. E. 2005. Cooperative Learning: Teori, Riset, dan Praktik. Terjemahan oleh Narulita Yusron. T.t. Bandung: Nusa Media

Sugiyono. 2012. Metode Penelitian Pendidikan Pendekatan Kuantitatif, Kualitatifdan $R \& D$. Bandung: Alfabeta

Syah, M. (2008). Psikologi Pendidikan dengan Pendekatan Baru. Bandung: PT. Remaja Rosda Karya

Tipa, D. S, Izaak, M. P \& Appulembang, O. D. (2016). A Journal of Language, Literature, Culture, and Education POLYGLOT, 12(2), 92-99 